\title{
Comment on: "Do We Have Enough Ophthalmologists to Manage Vision-Threatening Diabetic Retinopathy? A Global Perspective"
}

\author{
Thiago Gonçalves dos Santos Martins ${ }^{1,2}$ - Ana Luiza Fontes de Azevedo Costa ${ }^{1}$ Paulo Schor ${ }^{1}$
}

Received: 15 March 2020 / Revised: 8 April 2020 / Accepted: 15 April 2020 / Published online: 28 April 2020

(c) The Royal College of Ophthalmologists 2020

\section{To the Editor:}

In response to the article titled "Do We Have Enough Ophthalmologists to Manage Vision-Threatening Diabetic Retinopathy? A Global Perspective" published in your esteemed journal, I would like to raise a few points regarding this study. This is a well thought of and written paper which demonstrated that mild or moderate diabetic retinopathy could be adequately managed by primary care physicians, optometrists, and nurses. The conclusion was that the number of ophthalmologists differs greatly among the regions of the world with the highest density being in Europe (18.03) and the lowest density being in Africa (0.91) [1].

The time dedicated to teaching ophthalmology during medical education has been reduced over time. The number of colleges in countries such as the United States, which have a mandatory formal internship in ophthalmology, dropped from $68 \%$ in 2000 to $30 \%$ in 2004 [2]. In one study that analyzed medical records filled out by 364 thirdyear medical students, only $11 \%$ of the cases had documentation of the direct ophthalmoscopy exam, and only $2 \%$ suggested real observation of the retina [3]. Since $\sim 98 \%$ of medical graduates will not be ophthalmologists, we must develop better teaching methods so that primary care physicians, optometrists, and nurses can develop the necessary knowledge to properly conduct mild and moderate cases of diabetic retinopathy. This can be achieved with the development of low-cost direct ophthalmoscopy teaching models that allow students to have their own model to practice on as many times as necessary until they

\footnotetext{
Thiago Gonçalves dos Santos Martins

thiagogsmartins@yahoo.com.br

1 Federal University of São Paulo, Sao Paulo, Brazil

2 University of Coimbra, Coimbra, Portugal
}

feel confident to perform an adequate examination of the patients' retina [4].

The uneven distribution of ophthalmologists is also a problem inside the countries. Many of these professionals are concentrated in large hospitals of major cities. The need for eye care in the elderly is increasing in several developed countries, as are the cases of diabetic retinopathy. However, due to problems of urban mobility and uneven concentration of specialists, it becomes clear that a simple increase in the number of specialists will not be enough to improve the quality of ophthalmological care needed by the population [5]. The development of solutions such as telemedicine and artificial intelligence algorithms can help improve the quality of care for the population. Thus, better eye care and screening for the diabetic population can be achieved with the aid of training programs for primary care physicians, optometrists, and nurses, in addition to the use of the present technology to determine the early diagnosis and reduce the cost of the treatment of the complications caused by the diabetic retinopathy.

\section{Compliance with ethical standards}

Conflict of interest The authors declare that they have no conflict of interest.

Publisher's note Springer Nature remains neutral with regard to jurisdictional claims in published maps and institutional affiliations.

\section{References}

1. Teo ZL, Tham YC, Yu M, Cheng CY, Wong TY, Sabanayagam C. Do we have enough ophthalmologists to manage vision-threatening diabetic retinopathy? A global perspective. 2020. Eye. 2020. https://doi.org/10.1038/s41433-020-0776-5.

2. Quillen DA, Harper RA, Haik BG. Medical student education in ophthalmology: crisis and opportunity. Ophthalmology. 2005;112: 1867-8.

3. Harding SP, Broadbent DM, Neoh C, White MC, Vora J. Sensitivity and specificity of photography and direct ophthalmoscopy in 
screening for sight threatening eye disease: the Liverpool Diabetic Eye Study. BMJ. 1995;311:1131-5.

4. Martins TG, Costa ALF, Helene O, Martins RV, Helene AF, Schor P. Training of direct ophthalmoscopy using models. Clin Teach. 2017;14:1.
5. Resnikoff S, Lansingh VC, Washburn L, Felch W, Gauthier TM, Taylor HR, et al. Estimated number of ophthalmologists worldwide (International Council of Ophthalmology update): will we meet the needs? Br J Ophthalmol. 2020;104:588-92. 